\title{
$\begin{array}{ll}\text { Research Square } & \begin{array}{l}\text { Preprints are preliminary reports that have not undergone peer review. } \\ \text { They should not be considered conclusive, used to inform clinical practice, } \\ \text { or referenced by the media as validated information. }\end{array}\end{array}$
}

\section{Subjects living in an onchocerciasis focus and treated 3-monthly with ivermectin develop fewer new onchocercal nodules than subjects treated annually}

Jérémy Campillo ( $\square$ jeremycampillo34750@gmail.com )

Institut de recherche pour le developpement https://orcid.org/0000-0002-4400-5204

Cédric B. CHESNAIS

Institut de recherche pour le developpement

Sébastien D. Pion

Institut de recherche pour le developpement

Jacques Gardon

HydroSciences Montpellier

Joseph Kamgno

Centre de recherche sur les filarioses et autres maladies tropicales (CRFilMT)

Michel Boussinesq

Institut de recherche pour le developpement

\section{Research}

Keywords: Onchocerciasis, Onchocerca volvulus, Nodules, Onchocercoma, Ivermectin, Cameroon

Posted Date: February 5th, 2020

DOI: https://doi.org/10.21203/rs.2.22663/v1

License: (c) (i) This work is licensed under a Creative Commons Attribution 4.0 International License.

Read Full License

Version of Record: A version of this preprint was published at Parasites \& Vectors on May 15th, 2020. See the published version at https://doi.org/10.1186/s13071-020-04126-x. 


\section{Abstract}

\section{Background}

Little information is available on the effect of ivermectin on the third and fourth stage larvae of Onchocerca volvulus. To assess a possible prophylactic effect of ivermectin on this parasite, we compared the effects of different ivermectin regimens on the acquisition of onchocercal nodules.

\section{Methods}

We analyzed data from a controlled randomized clinical trial of ivermectin conducted in the Mbam valley (Cameroon) between 1994 and 1998 in a cohort of onchocerciasis infected individuals. The number of nodules that appeared between the start and the end of the clinical trial was analyzed, using ANOVA and multivariable Poisson regressions, between four treatment arms: $150 \mu \mathrm{g} / \mathrm{kg}$ annually, $800 \mu \mathrm{g} / \mathrm{kg}$ annually, $150 \mu \mathrm{g} / \mathrm{kg}$ 3-monthly, and $800 \mu \mathrm{g} / \mathrm{kg}$ annually.

\section{Results}

The mean number of nodules that appeared during the trial was reduced by $17.7 \%$ in subjects treated 3monthly compared to those treated annually (regardless of the dose). Poisson regression model, adjusting on subject's age and weight, initial number of nodules and intensity of $O$. volvulus infection in his village of residence, confirmed that the incidence of new nodules was reduced in 3-monthly treatment arms compared to annually treatment arms, and that the dosage of ivermectin does not seem to influence this effect. Besides, the number of newly acquired nodules was positively associated with the initial number of nodules. Analysis of disappearance of nodules did not show any significant difference between the treatment groups.

\section{Conclusions}

Our result suggest, for the first time in humans, that ivermectin has a prophylactic effect on 0 . volvulus . Three-monthly treatment seems more effective than annual treatment to prevent the appearance of nodules.

\section{Background}

Human onchocerciasis, also called "river blindness", is a neglected tropical disease (NTD) caused by the filarial nematode Onchocerca volvulus. In 1995, the World Health Organization (WHO) launched the African Programme for Onchocerciasis Control (APOC), which was mainly based on mass drug administration (MDA) of ivermectin (IVM). IVM, which is usually given annually at the standard dose of $150 \mu \mathrm{g} / \mathrm{kg}$ of body weight, has a direct effect on the microfilariae (mf) present in the skin (microfilaricidal effect) and prevents the release of new $\mathrm{mf}$ by the adult female worms for several months (embryostatic effect). However, the effect of IVM on the viability of the adult worms (macrofilaricidal effect) is considered as moderate and treatments have to be repeated every year (or at shorter intervals) to 
maintain skin microfilarial densities (MFD) at low levels not associated with clinical manifestations. Besides this, little information is available on the effect of IVM on the third and fourth stage larvae (L3s and L4s) which develop to the adult stage during the first months following the bite of an infective black fly, and on the immature adults. The effect on these L3s, L4s, and immature adults, which would prevent the development up to the stage of fecund adult worms releasing $\mathrm{mf}$, has been called causal prophylaxis, or suppressive effect [1]. We will use the term "prophylactic effect" throughout the text below.

Only three in vivo studies were conducted to evaluate the prophylactic effect of IVM on Onchocerca sp. The first one included 18 chimpanzees experimentally infected with 0 . volvulus. Six animals were treated with IVM (at $200 \mu \mathrm{g} / \mathrm{kg}$ ) on the day of inoculation of the L3s, 6 were treated on day 28 and 6 were not treated. After having followed up the development of infection by repeated skin biopsies for 30 months, the authors concluded that IVM could have a partial effect on the L3s (which live for about one week in the definitive host before molting to the L4 stage), but no effect on the L4s [2]. The second study was conducted in an area of North Cameroon where the cattle parasite 0 . ochengi is endemic. Two groups of calves between 2 and 8 weeks of age were treated monthly with subcutaneous IVM (Ivomec ${ }^{\circledR}$ ) at either $200 \mu \mathrm{g} / \mathrm{kg}$ or $500 \mu \mathrm{g} / \mathrm{kg}$ for 21 months, and a third group was left untreated. Before each treatment, the animals were palpated for 0 . ochengi nodules and underwent a skin biopsy. The fact that none of the 15 treated calves developed adult worm infection, whereas 5 of the 6 control calves became infected led the authors to conclude that IVM had an effect on the L3s and L4s of O. ochengi [3]. The third study was conducted in an onchocerciasis hyperendemic focus (Mbam valley, Cameroon) and included subjects with no 0 . volvulus $\mathrm{mf}$ in skin biopsies ("skin snips" taken with a $2 \mathrm{~mm}$ Holth punch). These subjects were treated, just after the start of the high transmission period, with either a single oral dose of IVM $(150 \mu \mathrm{g} / \mathrm{kg})$ plus ferrous sulphate tablets, or the latter drug only. One year after, the incidence of 0 . volvulus microfilaridermia was $23.4 \%$ in the IVM group and $25.8 \%$ in the control group, and the mean MFD were similar in the two groups (2.2 and $2.7 \mathrm{mf}$ per skin snip, respectively). The authors concluded that a single dose of IVM had no perceptible prophylactic effect in this highly endemic area [4]. Besides these trials, the effect of IVM on L3s and the L3-L4 molting process was supported by in vitro studies using Onchocerca lienalis $[5,6]$.

A double-blind randomized controlled trial aimed at assessing the potential macrofilaricidal effect of high (400-800 $\mu \mathrm{g} / \mathrm{kg}$ ) and/or more frequent (3-monthly) doses of IVM on 0 . volvulus was conducted in the Mbam valley (Cameroon) between 1994 and 1998. This effect was evaluated by the histologic examination of sections of nodules collected at the outset and at the end of the trial [7]. The proportion of dead female worms was found to be higher in the nodules collected from subjects treated 3-monthly than in those treated annually. During this trial, a careful examination for all palpable nodules was conducted at the outset of the trial, and during the nodulectomy round organized in 1997. The number and the location of each palpated nodule was noted on a standard chart. In the present paper, we present the results of statistical analyses performed on the number of nodules which had appeared or disappeared between the two examination rounds. Our main objective was to assess whether high doses or more frequent IVM treatment was associated with a lower number of new nodules (suggesting a prophylactic effect). Analyses were also performed on the number of nodules that had spontaneously disappeared. 


\section{Methods}

\section{Study population and subjects}

The protocol of the trial has been described in details elsewhere [7]. Briefly, it was conducted in the Bafia health district, located in the onchocerciasis hyperendemic focus of the Mbam valley (Cameroon). Eligible subjects were males aged 18-60 years in a good state of health, with no contra-indication to IVM, and who presented at least two palpable nodules at the outset of the trial.

\section{Procedures}

After having signed an informed consent form, subjects were randomly allocated to one of the four treatment groups receiving either $150 \mu \mathrm{g} / \mathrm{kg}$ annually (control group), or high dose (400 $\mu \mathrm{g}$, then $800 \mu \mathrm{g} / \mathrm{kg}$ ) annually, or $150 \mu \mathrm{g} / \mathrm{kg}$ 3-monthly or high dose 3-monthly. The pre-treatment nodulectomy round was performed in May-June 1994. Before the nodulectomy, each participant was carefully examined and the location of each palpable nodule was noted on a standard anatomic chart. The randomly selected nodule to remove during the operation was represented by a green dot on the chart, and all the others were noted as a red dot. After nodulectomy, each participant received a $150 \mu \mathrm{g} / \mathrm{kg}$ "clearing dose" of IVM $(150 \mu \mathrm{g} / \mathrm{kg})$ to avoid the possibility of severe reactions developing in any patients subsequently taking their first dose on the high-dose regimen. The 3-year courses of treatment under investigation began in August, 1994, 2-3 months after the clearing dose. A total of 643 subjects participated in this treatment round. The second round of nodulectomy was organized in August 1997. A total of 102 subjects was lost between August 1994 and August 1997 (24 deaths, 17 excluded on medical grounds and 61 subjects who moved away or were excluded because they missed one treatment round). The number of subjects participating in the second nodulectomy round was thus 541 . Before the collection of the nodules, each patient was reexamined and the location of the nodules present was noted on the anatomic chart used in 1994. The nodules which had spontaneously disappeared in the interval were noted, and the location of the nodules which had appeared between 1994 and 1997 (thereafter called "new nodules") were noted by a blue dot. As these examinations had been performed just before the operation, an additional clinical examination was performed in November 1997, i.e. in a less timeconstrained context, to confirm the results obtained three months before. This examination could be performed in 485 subjects and the statistical analyses were conducted on the latter.

The study protocol has been approved by the Ethical Committee of the Cameroon.

\section{Statistical Analysis}

Variables of interest were defined as (a) the number of nodules which appeared between 1994 and 1997 and (b) the number of nodules which disappeared. For these two variables, we used the same statistical analysis plan (Fig. 1). Firstly, we assessed the difference between people treated annually and people treated 3-monthly, regardless of the dose, using a Student test. Then, comparisons were performed 
between the four treatment arms using an ANOVA. A Bonferroni test was subsequently used to assess which treatment arm(s) differed from the others. In case of ANOVA-associated P-value $<0.250$, we planned to perform a multivariable analysis to assess the possible associations between appearance/disappearance of new nodules and the following variables: treatment group as categorical variable (firstly considering annual arms versus 3-monthly arms, then considering the four treatment arms), subject's age (expressed as continuous variable), subject's weight (continuous variable), initial number of palpable nodules (expressed sequentially as a continuous variable and as a categorical variable using the following categories: $<5$ nodules and $\geq 5$ nodules) and intensity of 0 . volvulus infection in the participant's village of residence. The latter variable was expressed in three categories (low, moderate and high intensity) and was defined according to the community microfilarial load (CMFL) in the community measured during previous parasitological surveys in the community itself, or in neighboring communities located at the same distance from the Mbam River. The CMFL, a classical indicator used to express the intensity of infection with 0 . volvulus in a community, corresponds to the geometric mean MFD (expressed as number of $\mathrm{mf}$ per skin snip) in subjects aged $\geq 20$ years [8]. The three categories used in the analyses correspond to CMFL $<20 \mathrm{mf} / \mathrm{skin}$ snip, [20-50[ $\mathrm{mf} / \mathrm{skin}$ snip and $\geq$ $50 \mathrm{mf} / \mathrm{skin}$ snip. Multivariable logistic regression models were used with the dependent variable coded as a binary outcome (appearance of nodules versus no appearance of nodule). The reference group is defined as people with less than 5 nodules in the $150 \mu \mathrm{g} / \mathrm{kg}$ 3-monthly treatment group. Then, Poisson regression models were used, with the dependent variable recoded as $0,1,2,3,4$ and $\geq 5$ new nodules. We estimated 2 models: one with the 4 treatment arms and one with the pooled annual and 3-monthly treatment arms, regardless of the dose. For all models, an interaction term between the treatment arm and the initial number of nodules was added to assess the mean number of new nodules according to these two variables simultaneously. We presented regression coefficients and their confidence intervals at $95 \%(95 \% \mathrm{Cl})$. The reference group is defined as people who had the lowest number of initial nodules (i.e. 2 nodules) in the $150 \mu \mathrm{g} / \mathrm{kg}$ annually group or in the annual treatment, depending on the model. According to this regression analysis, predictions were made using the margins and marginsplot commands. All analyses were performed using the STATA v.15.1 software (StatCorps, LP, College Station, TX, USA).

\section{Results}

\section{Baseline characteristics}

Table 1 presents the baseline characteristics of the 485 study subjects as a whole and in each treatment arm. Before the first nodulectomy round, the participants of the four treatment groups were similar in terms of age, body weight, mean number of nodules and CMFL in the village of residence. 
Table 1

Baseline characteristics of the subjects included in 1994, before the start of the clinical trial

\begin{tabular}{|c|c|c|c|c|c|}
\hline & $\begin{array}{l}\text { All } \\
\text { participants }\end{array}$ & $\begin{array}{l}150 \mu \mathrm{g} / \mathrm{kg} \\
\text { annually }\end{array}$ & $\begin{array}{l}800 \mu \mathrm{gg} / \mathrm{kg} \\
\text { annually }\end{array}$ & $\begin{array}{l}150 \mu \mathrm{gg} / \mathrm{kg} \\
\text { 3-monthly }\end{array}$ & $\begin{array}{l}800 \mu \mathrm{g} / \mathrm{kg} \\
\text { 3-monthly }\end{array}$ \\
\hline No. of subjects & 485 & 126 & 122 & 125 & 112 \\
\hline Mean age (SD) & $36.9(12.0)$ & $36.4(11.4)$ & $38.1(12.4)$ & $\begin{array}{l}36.7 \\
(11.9)\end{array}$ & $\begin{array}{l}36.6 \\
(12.3)\end{array}$ \\
\hline Mean weight $(\mathrm{kg})(\mathrm{SD})$ & $63.0(8.0)$ & $62.7(8.2)$ & $64.3(7.1)$ & $62.4(8.5)$ & $62.7(8.0)$ \\
\hline $\begin{array}{l}\text { Mean no. of nodules in } \\
1994 \text { (SD) }\end{array}$ & $5.7(2.8)$ & $5.5(2.5)$ & $5.8(2.3)$ & $5.6(3.2)$ & $5.9(2.9)$ \\
\hline $\begin{array}{l}\text { Median no. of nodules } \\
\text { in } 1994 \text { (IQR) }\end{array}$ & $5(4-7)$ & $5(4-7)$ & $6(4-7)$ & $5(3-7)$ & $6(4-7)$ \\
\hline \multicolumn{6}{|l|}{$\begin{array}{l}\text { CMFL in the village of } \\
\text { residence: }\end{array}$} \\
\hline$\cdot \operatorname{Low}(\mathrm{N}, \%)$ & $50(10.3 \%)$ & $10(7.9 \%)$ & $12(9.8 \%)$ & $\begin{array}{l}18 \\
(14.4 \%)\end{array}$ & $10(8.9 \%)$ \\
\hline - Middle (N, \%) & $\begin{array}{l}135 \\
(27.8 \%)\end{array}$ & 39 (31.0\%) & $37(30.3 \%)$ & $\begin{array}{l}30 \\
(24.0 \%)\end{array}$ & $\begin{array}{l}29 \\
(25.9 \%)\end{array}$ \\
\hline$\cdot \operatorname{High}(\mathrm{N}, \%)$ & $\begin{array}{l}300 \\
(61.9 \%)\end{array}$ & 77 (61.1\%) & $73(59.8 \%)$ & $\begin{array}{l}77 \\
(61.6 \%)\end{array}$ & $\begin{array}{l}73 \\
(65.2 \%)\end{array}$ \\
\hline
\end{tabular}

\section{Analysis Of Appearance Of Nodules Between 1994 And 1997}

The mean number of new nodules in the 237 subjects treated 3-monthly (1.85) was $17.7 \%$ lower than in the 248 subjects treated annually $(2.25$; Student test: $P=0.008)$. The mean numbers of nodules that appeared between 1994 and 1997 in subjects of each treatment group are shown in Table 2. ANOVA indicated a statistically significant difference in the number of new nodules between the treatment groups $(P=0.014)$. Bonferroni correction showed that the number of new nodules was significantly lower in the group which had received $150 \mu \mathrm{g} / \mathrm{kg}$ 3-monthly than in the group treated with $800 \mu \mathrm{g} / \mathrm{kg}$ annually $(P=0.008)$. No significant difference was found between the two groups treated annually $(P=1.000)$, nor between the two groups treated 3-monthly $(P=0.871)$, nor between the two groups treated with $150 \mu \mathrm{g} / \mathrm{kg}$ (annually vs 3-monthly) $(P=0.260)$. 
Table 2

Appearance and disappearance of the nodules after 3 years of treatment

\begin{tabular}{|lllllll|}
\hline & $\begin{array}{l}\text { All } \\
\text { participants }\end{array}$ & $\begin{array}{l}\mathbf{1 5 0} \boldsymbol{\mu g} / \mathbf{k g} \\
\text { annually }\end{array}$ & $\begin{array}{l}\mathbf{8 0 0} \boldsymbol{\mu g} / \mathbf{k g} \\
\text { annually }\end{array}$ & $\begin{array}{l}\mathbf{1 5 0} \boldsymbol{\mu g} / \mathbf{k g} \\
\text { 3-monthly }\end{array}$ & $\begin{array}{l}\mathbf{8 0 0} \boldsymbol{\mu g} / \mathbf{k g} \\
\text { 3-monthly }\end{array}$ & P \\
\hline No. subjects & 485 & 126 & 122 & 125 & 112 & \\
\hline $\begin{array}{l}\text { Mean no. of new } \\
\text { nodules (SD) }\end{array}$ & $2.1(1.7)$ & $2.1(1.7)$ & $2.4(1.8)$ & $1.7(1.5)$ & $2.0(1.6)$ & 0.014 \\
$\begin{array}{l}\text { Mean no. of } \\
\text { nodules that } \\
\text { disappeared (SD) }\end{array}$ & $0.5(0.8)$ & $0.5(0.8)$ & $0.5(0.7)$ & $0.6(0.8)$ & $0.6(0.8)$ & 0.279 \\
\hline \begin{tabular}{l} 
no.: number; SD: standard deviation \\
\hline
\end{tabular} & & & & & & \\
\hline
\end{tabular}

According to the logistic regression analysis (Table 3), the probability to develop new nodules did not differ significantly between the treatment groups of subjects with less than 5 palpable nodules. In addition, people with more than 5 nodules and belonging to the groups treated annually with $150 \mu \mathrm{g} / \mathrm{kg}$ and $800 \mu \mathrm{g} / \mathrm{kg}$ had, respectively, 3.8 and 5.3 more chance to have new nodule(s) than those treated with $150 \mu \mathrm{g} / \mathrm{kg}$ 3-monthly and with less than 5 nodules. 
Table 3

Logistic regression of the appearance of nodules

\begin{tabular}{|c|c|c|}
\hline Appearance of nodule(s) (Yes/No) & $\mathrm{OR}[95 \% \mathrm{Cl}]$ & $\mathbf{P}$ \\
\hline \multicolumn{3}{|l|}{ Less than 5 nodules: } \\
\hline $150 \mu \mathrm{g} / \mathrm{kg}$ 3-monthly $(\mathrm{n}=66)$ & Ref. & \\
\hline $150 \mu \mathrm{g} / \mathrm{kg}$ annually $(\mathrm{n}=77)$ & $1.6[0.6-3.8]$ & 0.315 \\
\hline $800 \mu \mathrm{g} / \mathrm{kg}$ 3-monthly $(\mathrm{n}=54)$ & $2.6[0.9-7.8]$ & 0.088 \\
\hline $800 \mu \mathrm{g} / \mathrm{kg}$ annually $(\mathrm{n}=58)$ & $0.9[0.4-2.15]$ & 0.829 \\
\hline \multicolumn{3}{|l|}{ More than 5 nodules: } \\
\hline 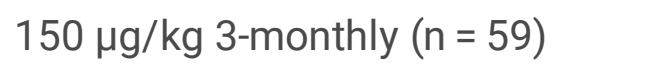 & $0.8[0.3-1.9]$ & 0.609 \\
\hline $150 \mu \mathrm{g} / \mathrm{kg}$ annually $(\mathrm{n}=49)$ & $3.8[1.0-14.4]$ & 0.047 \\
\hline $800 \mu \mathrm{g} / \mathrm{kg}$ 3-monthly $(\mathrm{n}=58)$ & $1.2[0.5-3.0]$ & 0.705 \\
\hline $800 \mu \mathrm{g} / \mathrm{kg}$ annually $(\mathrm{n}=64)$ & $5.3[1.4-19.7]$ & 0.013 \\
\hline Age & $1.0[1.0-1.0]$ & 0.916 \\
\hline Weight & $1.0[1.0-1.0]$ & 0.516 \\
\hline \multicolumn{3}{|l|}{ CMFL in the village of residence } \\
\hline Low & Ref. & \\
\hline Middle & $1.2[0.5-3.0]$ & 0.636 \\
\hline High & $1.3[0.6-3.0]$ & 0.465 \\
\hline
\end{tabular}

Table 4 shows the results of the Poisson regression model for each frequency of treatment explaining the count of new nodules. It shows that 3-monthly treatment (regression coefficient $=0.027 ; 95 \% \mathrm{Cl}=[0.005-$ 0.501]), whatever the dose, is more than twice effective than annual treatment (regression coefficient $=$ $0.061[0.036-0.086])$ to prevent the appearance of nodules. The difference in the slope is significant $(P=$ 0.001). Figure 2 represents the predictions of this model. Table 5 shows the results of the Poisson regression model including the four treatment arms separately. As shown in Figs. 2 and 3, these models reveal a strong interaction between the initial number of nodules and the predicted number of new nodules. It shows that in subjects treated 3-monthly (either with $150 \mathrm{or} 800 \mu \mathrm{g} / \mathrm{kg}$ ) fewer nodules had appeared than in subjects treated annually (with 150 or $800 \mu \mathrm{g} / \mathrm{kg}$ ), and that the difference of appearance was highly correlated with the initial number of nodules harboured by the participants. In 
addition, treatment with high IVM dose does not seem to influence the number of new nodules, regardless of the number of initial palpable nodules.

Table 4

Poisson regression model with pooled arms

\begin{tabular}{|c|c|c|}
\hline & $\mathrm{B}[95 \% \mathrm{Cl}]$ & $\mathbf{P}$ \\
\hline \multicolumn{3}{|c|}{ Increase in no. of new nodules for each additional initial nodule* } \\
\hline Annual treatment & $0.061[0.036-0.086]$ & $<0.001$ \\
\hline 3-monthly treatment & $0.027[0.005-0.050]$ & 0.018 \\
\hline Age & $0.003[-0.002-0.008]$ & 0.240 \\
\hline Weight & $-0.006[-0.014-0.002]$ & 0.154 \\
\hline \multicolumn{3}{|c|}{ CMFL in the village of residence } \\
\hline Low & Ref. & \\
\hline Middle & $0.085[-0.17-0.34]$ & 0.512 \\
\hline High & $0.148[-0.091-0.387]$ & 0.226 \\
\hline P of the model & $<0.001$ & \\
\hline AIC & 1661 & \\
\hline $\mathrm{BIC}$ & 1690 & \\
\hline Log likelihood & -823.6 & \\
\hline \multicolumn{3}{|c|}{ * The reference is defined as annual treatment and 2 initial nodules } \\
\hline b: regression coefficie & & \\
\hline
\end{tabular}


Table 5

Poisson regression model (with interaction term between initial number of nodules and treatment arms)

\begin{tabular}{|c|c|c|}
\hline & $\mathrm{B}[95 \% \mathrm{Cl}]$ & $\mathbf{P}$ \\
\hline \multicolumn{3}{|c|}{ Increase in no. of new nodules for each additional initial nodule* } \\
\hline $150 \mu \mathrm{g} / \mathrm{kg}$ annually & $0.051[0.022-0.080]$ & 0.000 \\
\hline $800 \mu \mathrm{g} / \mathrm{kg}$ annually & $0.071[0.044-0.099]$ & 0.000 \\
\hline $150 \mu \mathrm{g} / \mathrm{kg}$ 3-monthly & $0.024[-0.001-0.050]$ & 0.062 \\
\hline $800 \mu \mathrm{g} / \mathrm{kg}$ 3-monthly & $0.031[0.004-0.059]$ & 0.026 \\
\hline Age & $0.003[-0.002-0.008]$ & 0.278 \\
\hline Weight & $-0.006[-0.015-0.002]$ & 0.125 \\
\hline \multicolumn{3}{|l|}{ CMFL in the village of residence } \\
\hline Low & Ref. & \\
\hline Middle & $0.083[-0.17-0.34]$ & 0.526 \\
\hline High & $0.146[-0.094-0.385]$ & 0.234 \\
\hline P of the likelihood-ratio test for the interaction term & 0.035 & \\
\hline P of the model & $<0.001$ & \\
\hline AIC & 1662 & \\
\hline $\mathrm{BIC}$ & 1713 & \\
\hline Log likelihood & -819.5 & \\
\hline \multicolumn{3}{|c|}{ * The reference is defined as $150 \mu \mathrm{g} / \mathrm{kg}$ annually and 2 initial nodules } \\
\hline
\end{tabular}

\section{Analysis Of Disappearance Of Nodules Between 1994 And 1997}

In the 248 subjects treated annually, the mean number of nodules which disappeared between 1994 and 1997 (0.46) was lower than in the 237 subjects treated 3-monthly (0.60) but the difference was not 
significant (Student test: $\mathrm{P}=0.0605$ ). The mean numbers of nodules that disappeared between 1994 and 1997 in subjects of each treatment group are shown in Table 2.

The ANOVA did not show any difference between the four groups $(P=0.279)$. In consequence, we did not perform further analysis on the disappearance of nodules.

\section{Discussion}

Our study is the first to compare the effect of various IVM treatment regimens on the appearance of new onchocercal nodules in human subjects exposed to transmission of 0 . volvulus. It demonstrates that the mean number of palpable nodules which appeared within the 3-year period of the trial was significantly lower in the individuals treated 3-monthly with IVM than in those treated annually, and that the high doses had no higher effect than standard doses in reducing the number of new nodules.

These results should be interpreted in the light of what is known on the biology of 0 . volvulus within the year following the infective bite. The modalities of development of 0 . volvulus between the penetration of the parasite into the host under the form of $L 3$, and the time when it is found as an adult fecund stage in a nodule are not fully known. The time of the L3-L4 molt has been assessed by in vitro studies and by infecting experimentally various animals with L3s of Onchocerca sp. The time of the final molt was evaluated by following up the appearance of antibodies which were assumed to be stage-specific. It appears that, for 0 . volvulus, the L3-L4 molt occurs within a week of inoculation [9], that the final molt producing immature adults occurs within 3-5 months, that the adults become sexually mature at 7.5-11 months, and that the first $\mathrm{mf}$ produced by the mature adult female worms can be detected after an average period of 12-15 months [10]. Thus, the lifespan of the immature adult worms would range between 2.5 months ( 7.5 minus 5$)$ and 8 months (11 minus 3$)$. Given this timeframe, one can consider that all the L4s present in an individual treated 3-monthly with IVM will be exposed once (if the L4s' lifespan is 3 months) or twice (if it is 5 months) to the drug, and that it would probably be the same for the immature worms. Conversely, only a small proportion of L3s "inoculated" to these subjects treated every 90 days would be exposed to the drug (5.6-7.8\% of the L3s if the L3-L4 molt occurs 5-7 days after the infective bite). If one assumes that the appearance (or not) of new nodules reflects the effect of the drug on the parasitic stages preceding the mature adult stage, which is debatable (see below), the observed decrease of $17.7 \%$ in the number of new nodules in the subjects treated 3-monthly suggests that the prophylactic effect of IVM is not limited to the effects of the drug on the L3s or on the L3-L4 molting process, but that IVM has also a partial effect on the L4s and/or the immature adult worms.

In this study, we assumed that the effect of a drug on the $L 4 s$ and immature adults can be assessed by following up the appearance of new nodules in hosts exposed to transmission of 0 . volvulus. This is debatable because the sites where the L4s and the immature adults live, and the modalities by which the adult female worms are finally found in a nodule are poorly known. In particular, the extent to which immature females are attracted by existing nodules or are able to create a new nodule are not known. According to Duke et al., "it is expected ... that the L4 will be highly mobile and capable (by means 
unknown) of locating the adult sites of election or (perhaps by means of pheromones) of finding preexisting worm bundles; and that the immature females may continue these wanderings, ..., but are then likely to settle down to form nodules of their own or to join pre-existing nodules. The possibility cannot be excluded that some of the immature females may remain dormant at a prepubertal phase, situated in the connective tissues away from the nodules" [9]. Guderian et al. compared the sites of appearance of new nodules in a group of subjects from whom all the palpable nodules had been removed and a group with no nodulectomy. They concluded that "It seems likely that young, female, unencapsulated 0 . volvulus are attracted to existing nodules, settle down next to them and then become encapsulated themselves"[11]. However, as it is admitted (a) that the female worms, once in a nodule, stay there, and (b) that nodules form around female worms (not male worms), one may assume that the appearance of a new nodule can occur only if new females have appeared. Therefore, the lower number of new nodules recorded in the groups treated 3-monthly, when compared to the annually-treated group, results probably from an at least partial effect of ivermectin on the $L 4 s$ and/or the juvenile female worms.

Specific study designs, using probably animal models, could be developed to evaluate the strength of this prophylactic effect after a single dose of IVM, which would help refine the mathematical models used to predict the impact of IVM MDA on onchocerciasis transmission intensity. Trials could also be conducted to define which treatment frequency would be required to obtain the best prophylactic effect. We found that 3-monthly treatments led to a significant reduction in the appearance of new nodules when compared to annual treatment but the difference was not very marked. Monthly treatments would probably lead to a stronger effect, as suggested by the results of the study conducted on the 0 . ochengi/cattle model [2]. Such monthly treatments have been used in studies evaluating their possible macrofilaricidal effect on 0 . volvulus [12] or their effect on Loa loa [13]. They probably cannot be applied on a large scale, but could be proposed to individuals visiting temporarily an onchocerciasis endemic area. Unlike loiasis which can be prevented using diethylcarbamazine (DEC) [14, 15], no prophylactic drug exists for onchocerciasis. Trials using DEC were conducted on chimpanzees experimentally infected with 0 . volvulus and on humans by looking at the effect of the drug on L3s, but the results were not conclusive [16].

A remaining question is why the difference of impact between 3-monthly and annual treatment is higher when the initial number of nodules is higher. Before the start of this study, some participants had more nodules than others. This variability can be explained by different levels of exposure to onchocerciasis transmission, but also by inter-individual heterogeneity in immunological response. Some individuals are more predisposed than other to tolerate incoming parasites, with a weaker immune response allowing more $L 3 s^{\prime}$ and $L 4 s^{\prime}$ developing to the adult stage, and therefore leading to more nodules. During the 3 years of the trial, it is very unlikely that these two factors changed for the participants. Then, it makes sense that the most infected people (i.e. with the highest number of nodules) at the start of the study, are also the most infected ones at the end of the trial.

Few studies tried to evaluate the impact of IVM treatment on nodules' disappearance. Duke et al. assessed this phenomenon by comparing patients who were given IVM at $150 \mu \mathrm{g} / \mathrm{kg} 3$-monthly and 
untreated persons. They described a higher proportion of nodules that had disappeared in the treated group but the difference was not significant [17]. Three other studies reported that nodules can disappear after repeated doses of IVM [18-20]. We did not find a difference in the number of nodules which disappeared between the treatment arms of our study, but this could be due to a lack of statistical power due to a too small sample size. Further studies have to be conducted to determine the impact of repeated doses of IVM on the nodules' disappearance.

\section{Conclusions}

This study provides evidence that 3-monthly treatment are more effective than annual treatment to prevent the appearance of onchocercal nodules. This effect is particularly marked in individuals with large number of nodules before treatment. Our result support, for the first time, that ivermectin has probably a prophylactic effect on the $L 4 s$ and/or the juvenile female 0 . volvulus worms.

\section{List Of Abbreviations}

NTD (Neglected Tropical Diseases), WHO (World Health Organization), MDA (mass drug administration), IVM (ivermectin), MFD (microfilarial densities), CMFL (community microfilarial loads), DEC (diethylcarbamazine).

\section{Declarations}

\section{Ethics approval and consent to participate}

This study is the follow-up of a clinical trial approved by the Ethics Committee of Cameroon. The participants in the initial clinical trial all provided written informed consent.

\section{Consent for publication}

Not applicable.

\section{Availability of data and materials}

The datasets used and/or analysed during the current study are available from the corresponding author on reasonable request. 
The authors declare that they have no competing interests.

\section{Funding}

The data were originally collected using funds from the River Blindness Foundation. No additional funds were required for this study.

\section{Authors' contributions}

MB designed the study. JC analyzed the data. JC wrote the first manuscript draft. CBC, SDP and MB reviewed and edited the manuscript. All authors read and approved the final version of the manuscript.

\section{Acknowledgments}

Not applicable.

\section{References}

1. Lämmler G. Experimental chemotherapy and chemoprophylaxis of filariasis. Pestic Sci. 1977;8:56376.

2. Taylor HR, Trpis M, Cupp EW, Brotman B, Newland HS, Soboslay PT, et al. Ivermectin Prophylaxis Against Experimental Onchocerca Volvulus Infection in Chimpanzees. Am J Trop Med Hyg. 1988;39:86-90.

3. Tchakouté VL, Bronsvoort M, Tanya V, Renz A, Trees AJ. Chemoprophylaxis of Onchocerca infections: In a controlled, prospective study ivermectin prevents calves becoming infected with $O$. ochengi. Parasitology. 1999;118:195-9.

4. Boussinesq M, Gardon J, Kamgno J, Demanga-Ngangue, Pion SDS, Duke BOL. Studies on the macrofilarial population of Onchocerca volvulus in hyper-endemic villages of the Central province of Cameroon. Ann Trop Med Parasitol. 2001;95:379-88.

5. Court J, Bianco A, Townson S, Ham P, Friedheim E. Study on the activity of antiparasitic agents against Onchocerca lienalis third stage larvae in vitro. Trop Med Parasitol. 1985;Jun;36(2):117-9.

6. Lok JB, Pollack RJ, Donnelly JJ. Studies of the Growth-Regulating Effects of Ivermectin on Larval Onchocerca lienalis In vitro. J Parasitol. 1987;73:80. 
7. Gardon J, Boussinesq M, Kamgno J, Gardon-Wendel N, Demanga-Ngangue, Duke BOL. Effects of standard and high doses of ivermectin on adult worms of Onchocerca volvulus: A randomised controlled trial. Lancet. 2002;360:203-10.

8. Remme JHF, Ba O, Dadzie KY, Karam M. A force-of-infection model for onchocerciasis and its applications in the epidemiological evaluation of the Onchocerciasis Control Programme in the Volta River basin area. 1986;64:667-81.

9. Duke BO, Pacqué MC, Muñoz B, Greene BM, Taylor HR. Viability of adult Onchocerca volvulus after six 2-weekly doses of ivermectin. Bull World Heal Organ. 1991;69:163-8.

10. Eberhard ML, Dickerson JW, Boyer AE, Tsang VCW, Zea-Flores R, Walker EM, et al. Experimental Onchocerca volvulus infections in mangabey monkeys (Cercocebus atys) compared to infections in humans and chimpanzees (Pan troglodytes). Am J Trop Med Hyg. 1991;44:151-60.

11. Guderian RH, Anselmi M, Espinel M, Mancero T, Rivadeneira G, Proaño R, et al. Successful control of onchocerciasis with community-based ivermectin distribution in the Rio Santiago focus in Ecuador. Trop Med Int Heal. 1997;2:982-8.

12. Duke BOL, Zea-Flores G, Castro J, Cupp EW, Muñoz B. Effects of Multiple Monthly Doses of Ivermectin on Adult Onchocerca volvulus. Am J Trop Med Hyg. 1990;43:657-64.

13. Kombila M, Duong TH, Ferrer A, Perret J-L, Marion M-C, Nguiri C, et al. Short- and Long-Term Action of Multiple Doses of Ivermectin on. Trop Med. 1998;58:458-60.

14. Duke BOL. Studies on the chemoprophylaxis of loiasis. Ann Trop Med Parasitol. 1963;55:447-51.

15. Nutman TB, Miller KD, Mulligan M, Reinhardt GN, Currie BJ, Steel C, et al. Diethylcarbamazine Prophylaxis for Human Loiasis. N Engl J Med. 1988;319:752-6.

16. Duke BO. Experiments on the chemoprophylaxis of Onchocerca volvulus infection. Bull World Health Organ. 1968;39:179-86.

17. Duke BOL, Zea-Flores G, Castro J, Cupp EW, Munoz B. Effects of three-month doses of ivermectin on adult Onchocerca volvulus. Am J Trop Med Hyg. 1992;46:189-94.

18. Emukah EC, Osuoha E, Miri ES, Onyenama J, Amazigo U, Obijuru C, et al. A longitudinal study of impact of repeated mass ivermectin treatment on clinical manifestations of onchocerciasis in Imo State, Nigeria. Am J Trop Med Hyg. 2004;70:556-61.

19. Ukaga CC, Dozie INS, Nwoke BEB. Validation of reports of nodules dissolution after repeated ivermectin treatment of onchocerciasis in Southeastern Nigeria. East Afr Med J. 2001;78:515-7. 
20. Anosike JC, Dozie INS, Ameh GI, Ukaga CN, Nwoke BEB, Nzechukwu CT, et al. The varied beneficial effects of ivermectin (Mectizan) treatment, as observed within onchocerciasis foci in south-eastern Nigeria. Ann Trop Med Parasitol. 2012;101:593-600.

\section{Figures}

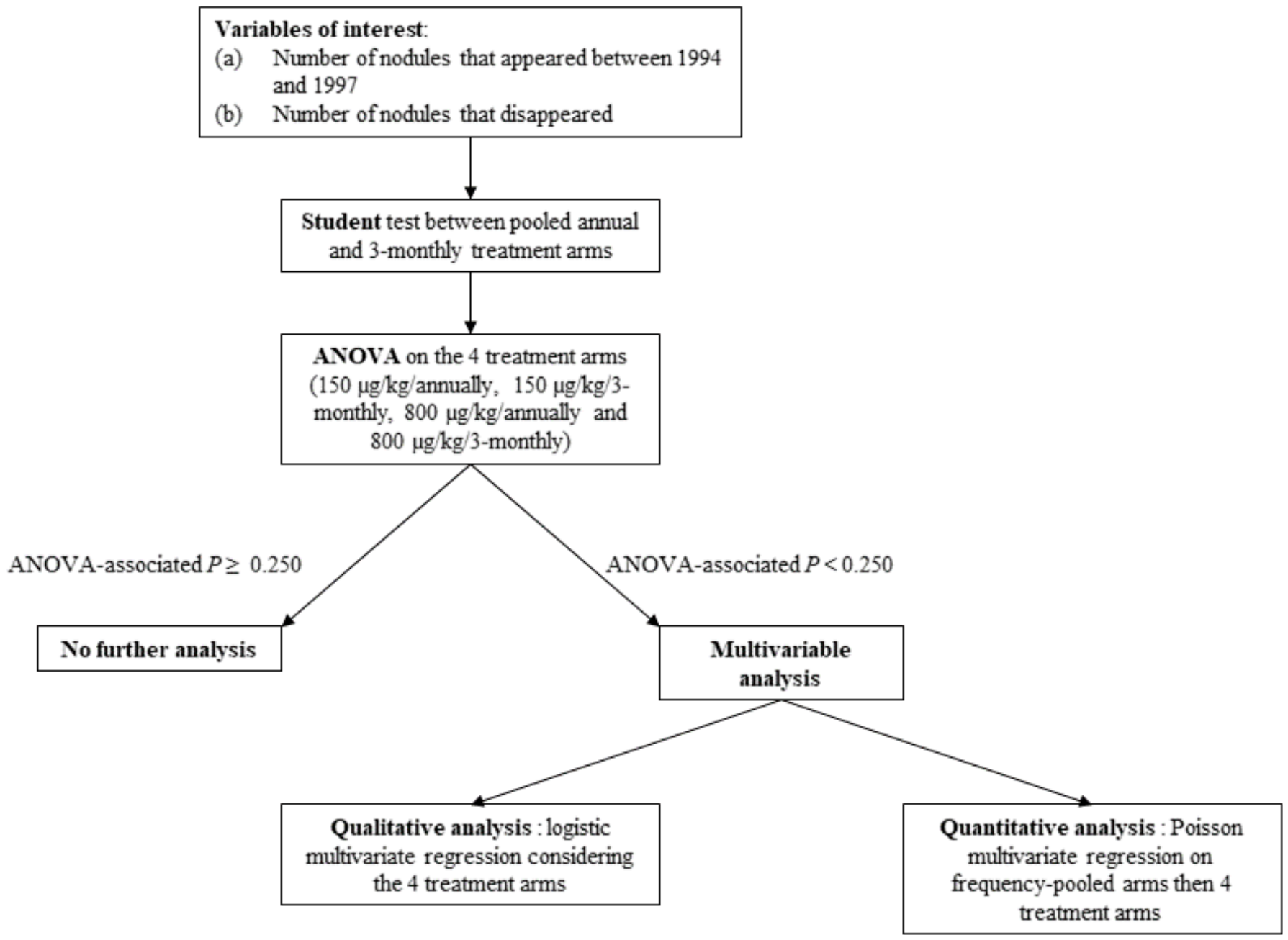

Figure 1

Statistical analysis plan 


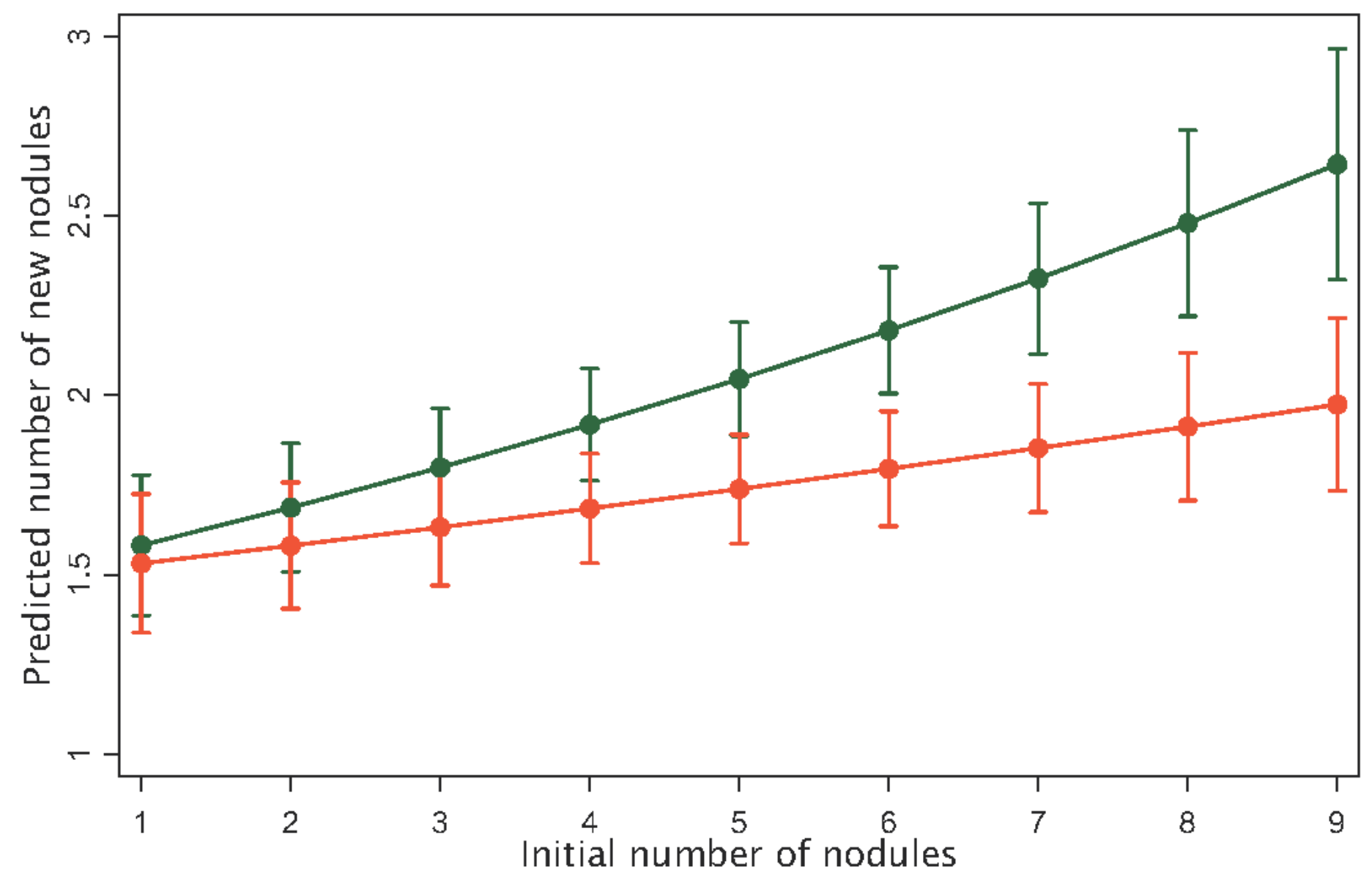

$\longmapsto$ Annual treatment $\longmapsto$ 3-monthly treatment

Figure 2

Predicted number of new nodules vs initial number of nodules (annual vs 3-monthly arms) Bars indicate $95 \%$ confidence intervals. 


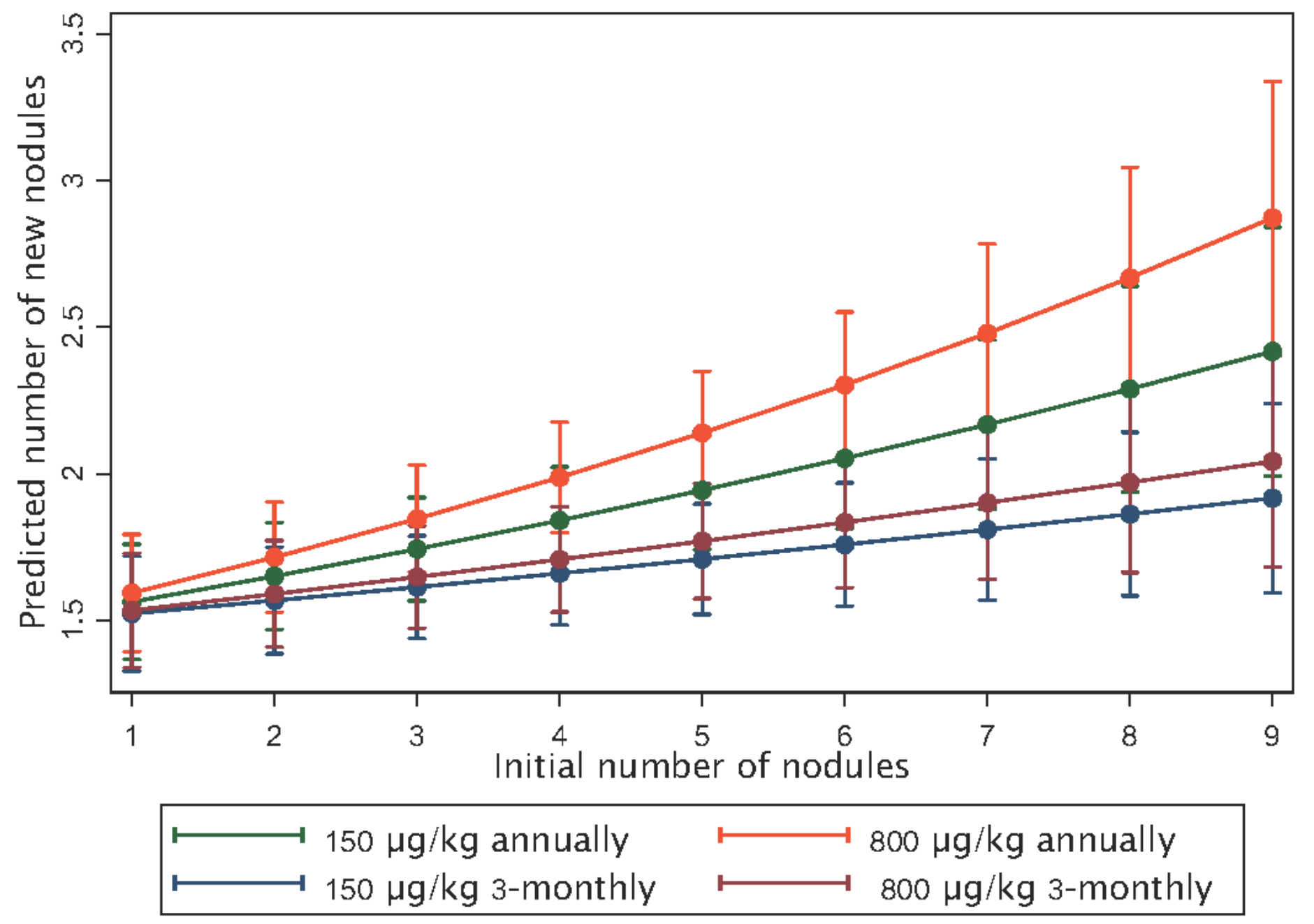

Figure 3

Predicted number of new nodules vs initial number of nodules (annual vs 3-monthly arms) Bars indicate $95 \%$ confidence intervals. 